Supplement of Biogeosciences, 18, 3751-3762, 2021 https://doi.org/10.5194/bg-18-3751-2021-supplement (C) Author(s) 2021. CC BY 4.0 License.

(c) (i)

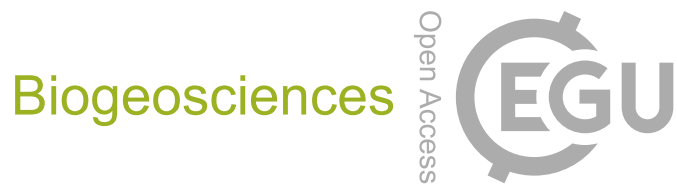

Supplement of

\title{
Evaluating the potential for Haloarchaea to serve as ice nucleating particles
}

Jessie M. Creamean et al.

Correspondence to: Jessie M. Creamean (jessie.creamean@colostate.edu) and Matthew E. Rhodes (rhodesme@cofc.edu)

The copyright of individual parts of the supplement might differ from the article licence. 
Table S1. Results for Fisher's exact test for intercomparisons of treatment data for H. morrhuae and H. sulfurifontis (i.e., data from Figures 2 and 3 in the manuscript). Data are binned and averaged for $0.5^{\circ} \mathrm{C}$ increments. The $p$ value is two-tailed and level of statistical significance in for the heat and peroxide treated spectra and provided compared to the unamended data. Significant, very significant, and extremely significant comparisons are noted by ***, and ***, respectively. Those which are not significant are left blank.

\begin{tabular}{|c|c|c|c|c|c|c|c|c|c|}
\hline \multirow[b]{2}{*}{$\begin{array}{c}\text { Haloarchaeal } \\
\text { species }\end{array}$} & \multirow[b]{2}{*}{$\begin{array}{l}\text { Dilution } \\
\text { factor }\end{array}$} & \multirow[b]{2}{*}{$\begin{array}{c}\text { Freezing } \\
\text { temperature }\end{array}$} & \multirow[b]{2}{*}{$\begin{array}{l}\text { Unamended } \\
\text { fraction } \\
\text { frozen }\end{array}$} & \multicolumn{3}{|c|}{ Heat treated } & \multicolumn{3}{|c|}{ Peroxide treated } \\
\hline & & & & $\begin{array}{l}\text { Fraction } \\
\text { frozen }\end{array}$ & $\underset{\text { value }}{\mathbf{p}}$ & $\begin{array}{l}\text { Statistical } \\
\text { significance }\end{array}$ & $\begin{array}{l}\text { Fraction } \\
\text { frozen }\end{array}$ & $\underset{\text { value }}{\mathbf{p}}$ & $\begin{array}{c}\text { Statistical } \\
\text { significance }\end{array}$ \\
\hline \multirow{18}{*}{$\begin{array}{l}\text { Halococcus } \\
\text { morrhuae }\end{array}$} & \multirow{5}{*}{$1: 6$} & -18.5 & 0.04 & 0.00 & 1.0000 & \multirow{3}{*}{$*$} & 0.00 & 1.0000 & \\
\hline & & -19.0 & 0.23 & 0.00 & 0.0219 & & 0.00 & 0.0219 & $*$ \\
\hline & & -19.5 & 0.29 & 0.13 & 0.2865 & & 0.00 & 0.0094 & $* *$ \\
\hline & & -20.0 & 0.79 & 0.46 & 0.0355 & \multirow[t]{2}{*}{$*$} & 0.10 & 0.0001 & $* * *$ \\
\hline & & -20.5 & 1.00 & 0.81 & 0.1092 & & 0.23 & 0.0496 & $*$ \\
\hline & \multirow{7}{*}{$1: 15$} & -17.5 & 0.08 & 0.04 & 1.0000 & \multirow{7}{*}{$\begin{array}{l}* * \\
*\end{array}$} & 0.00 & 0.4894 & \\
\hline & & -18.0 & 0.08 & 0.04 & 1.0000 & & 0.00 & 0.4894 & \\
\hline & & -18.5 & 0.08 & 0.04 & 1.0000 & & 0.00 & 0.4894 & \\
\hline & & -19.0 & 0.31 & 0.17 & 0.3177 & & 0.00 & 0.0039 & $* *$ \\
\hline & & -19.5 & 0.75 & 0.29 & 0.0034 & & 0.00 & 0.0001 & $* * *$ \\
\hline & & -20.0 & 0.98 & 0.71 & 0.0479 & & 0.08 & 0.0001 & $* * *$ \\
\hline & & -20.5 & 1.00 & 1.00 & 1.0000 & & 0.08 & 0.0001 & $* * *$ \\
\hline & \multirow{6}{*}{$1: 30$} & -18.5 & 0.04 & 0.00 & 1.0000 & \multirow{6}{*}{$\begin{array}{l}* * \\
* * *\end{array}$} & 0.00 & 1.0000 & \\
\hline & & -19.0 & 0.08 & 0.00 & 0.4894 & & 0.00 & 0.4894 & \\
\hline & & -19.5 & 0.29 & 0.08 & 0.1365 & & 0.00 & 0.0094 & $* *$ \\
\hline & & -20.0 & 0.69 & 0.19 & 0.0012 & & 0.04 & 0.0001 & $* * *$ \\
\hline & & -20.5 & 0.94 & 0.50 & 0.0007 & & 0.13 & 0.0001 & $* * *$ \\
\hline & & -21.0 & 1.00 & 0.92 & 0.4894 & & 0.13 & 0.0001 & $* * *$ \\
\hline \multirow{4}{*}{$\begin{array}{l}\text { Haloferax } \\
\text { sulfurifontis }\end{array}$} & \multirow{4}{*}{$1: 15$} & -19.0 & 0.04 & 0.00 & 1.0000 & & 0.08 & 1.0000 & \\
\hline & & -19.5 & 0.04 & 0.00 & 1.0000 & & 0.13 & 0.6085 & \\
\hline & & -20.0 & 0.04 & 0.00 & 1.0000 & & 0.13 & 0.6085 & \\
\hline & & -20.5 & 0.23 & 0.00 & 0.0496 & $*$ & 0.13 & 0.7008 & \\
\hline
\end{tabular}




\begin{tabular}{llllllll}
-21.0 & 0.38 & 0.00 & 0.0016 & $* *$ & 0.17 & 0.1930 & \\
-21.5 & 0.42 & 0.04 & 0.0044 & $* *$ & 0.17 & 0.1107 & \\
-22.0 & 0.48 & 0.04 & 0.0018 & $* *$ & 0.21 & 0.1246 & $* * *$ \\
-22.5 & 0.75 & 0.08 & 0.0001 & $* * *$ & 0.21 & 0.0004 & $* * *$ \\
-23.0 & 0.81 & 0.13 & 0.0001 & $* * *$ & 0.25 & 0.0001 & $* * *$ \\
-23.5 & 0.88 & 0.13 & 0.0001 & $* * *$ & 0.29 & 0.0001 & $* * *$ \\
-24.0 & 0.88 & 0.13 & 0.0001 & $* * *$ & 0.33 & 0.0003 & $* * *$ \\
-24.5 & 0.88 & 0.17 & 0.0001 & $* * *$ & 0.38 & 0.0008 & $* *$ \\
-25.0 & 0.92 & 0.31 & 0.0001 & $* * *$ & 0.54 & 0.0078 & \\
-25.5 & 0.92 & 0.44 & 0.0130 & $* *$ & 0.79 & 0.4158 & \\
-26.0 & 0.96 & 0.63 & 0.0102 & $*$ & 0.92 & 1.0000 & \\
-26.5 & 1.00 & 0.79 & 0.0496 & $*$ & 1.00 & 1.0000 & \\
\hline
\end{tabular}

